\title{
The Methodology of Economic Costs Influential on Automation of Component Production
}

\author{
Darina Matisková \\ Technical University in Kosice, Faculty of Manufacturing Technologies with seat in Presov, Department of Manufacturing Management, \\ Bay erova, 1, 080 01, Presov, Europa, Slovakia
}

\begin{abstract}
This article is about determine the optimalization and minimalization of costs from automation production for small and middle enterprices of mathematical methods. The transition from current engineering to the complex auto mated and highly machanical production is inevitable. The economic aspects on optimalization of components production are nowadays very current issue. At the time of ongoing world economic crisis the most discussed topic in this area as well is the decreasing of the production costs. When cutting conditions and tool durability optimizing, it is necessary to apply certain optimizing criterion with in certain restraining conditions. The restrictions are given by technical parameters of a machine, tool, machined material, required quality of machined surface etc. The essential economic criterion is the amount of production cost.
\end{abstract}

Keywo rds Economic Reasons, Production of Costs, Minimalization of Costs, Optimizing, Machine Serviceability

\section{Introduction}

When considering machining process from the point of efficiency (productivity) production costs are oblivious. Yet, It is applicable exceptionally.

In market mechanis $m$ it is required to produce a product in such economic conditions so that its sale price be acceptable and attractive. To start thinking about a production process it is necessary to get an idea about its cost structure.

When machining, it is important to consider engaging movement of particular machines. At more difficult optimization it is possible to source from single-machine optimization.

Optimization of cutting conditions is convenient to realize by a complex calculation whose outputs are optimal values of cutting conditions and durability of a cutting wedge. According to complexity it is necessary to use a computer with appropriate software.

Using more expensive production installation the costs raise more rapidly. They reach minimum at higher cutting speed than when utilizing usual mach ines. Disobedience to this relation leads to sharp rise of production costs when machining using the CNC machines. The basic cost development scheme is in the fig. 1..(1)

When considering machining process from the point of efficiency (productivity) production costs are oblivious. Yet, It is applicable exceptionally.

* Corresponding author:

darina.matiskova@gmail.com (Darina Matisková)

Published online at http://journal.sapub.org/economics

Copyright (C) 2012 Scientific \& Academic Publishing. All Rights Reserved
In market mechanis $m$ it is required to produce a product in such economic conditions so that its sale price be acceptable and attractive. To start thinking about a production process it is necessary to get an idea about its cost structure.

When machining, it is important to consider engaging movement of particular machines. At more difficult optimization it is possible to source from single-machine optimization.

\section{Explanation of Methods}

Optimization of cutting conditions is convenient to realize by a complex calculation whose outputs are optimal values of cutting conditions and durability of a cutting wedge. According to complexity it is necessary to use a computer with appropriate software.

It is worth to comment that if ,universal“ software for optimization usable without an input of a particular company data are commercially offered it is not possible to speak about optimization. The optimization is dependent on particular conditions of every company. The software represents only basic recommendation what cutting conditions to determine. Real optimal values can markedly differ fro $m$ these cutting conditions.(2), (3), (6)

In present, the cutting conditions are mainly chosen from norms that is not optimal. The nature of cutting conditions optimization is to determine optimal values of given conditions (cutting depth $-a_{p}$, underthrust depth $-f$, cutting speed $\left.-v_{c}\right)$ and the optimization of a machine durability. 
The criterion for minimum costs is the basic optimization criterion in engineering technology. It should be applied on principle.

We attempt to describe the criteria for minimum production costs. We shall consider only the costs items that are dependent on cutting conditions. Consequently, total costs may be given by the relation:
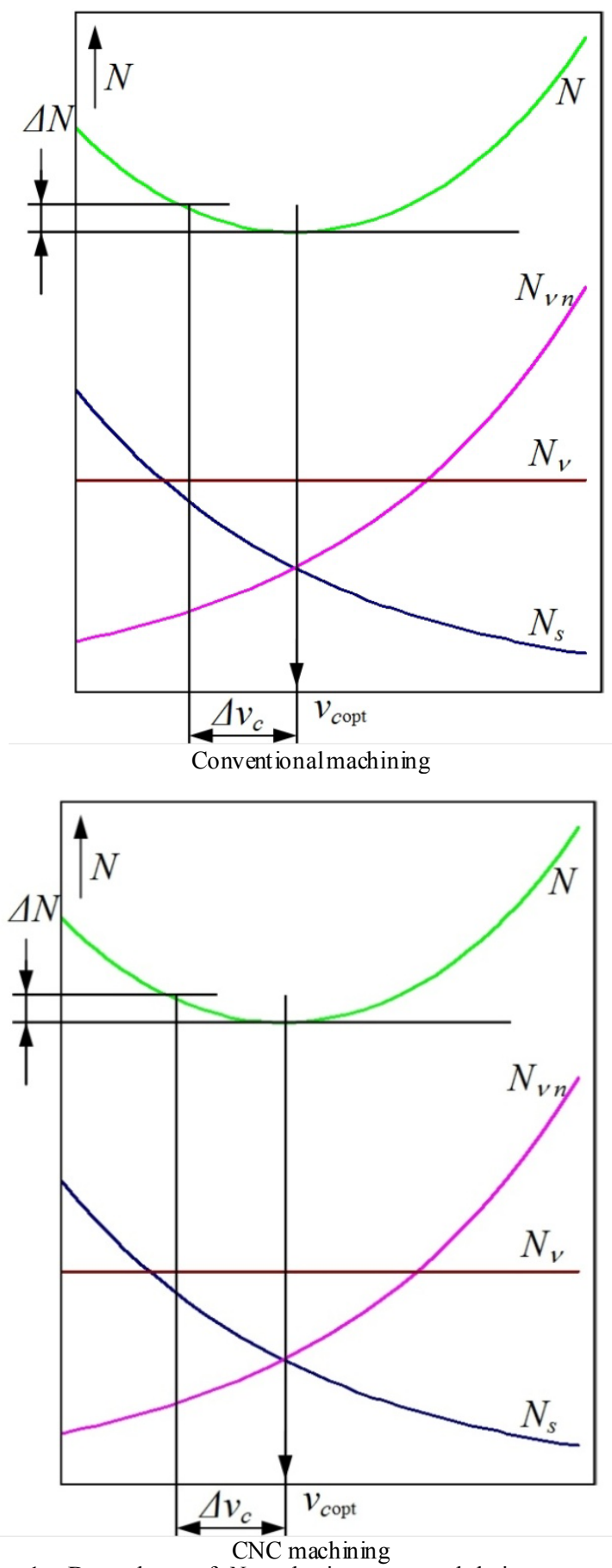

Figure 1. Dependence of $N$ production costs and their components on cutting speed $v_{c} . N_{c}$ - costs on machine work, $N_{v}$ - secondary work costs, $N_{v n}$ - costs to device exchange

$$
N_{c}=N_{s}+N_{n}+N_{m}
$$

where:

$N$ - production costs to calculate an operational section, $[€]$,

$N_{s}$ - costs to machine labor per an operational section, $[€]$,

$N_{n}$ - costs to machines related to the operational section, $[€]$,

$N_{v n}$ - costs to exchange or offset of a worn-out device related to the operational section, $[€]$,

Individual cost units may be formu lated as follows:

For labor costs of a machine holds:

$$
N_{s}=\tau_{A s}\left[k_{c} \frac{M_{o}}{60}\left|1+\frac{R N S_{p l}}{100}\right|+\frac{N_{h s}}{60}\right]=\tau_{A S} N_{s m}
$$

Where:

$N_{s m}$ are costs to one minute machine labor, [€. $\min ^{-1}$,

$N_{h s}$ - hourly costs to machine operation, [€. $h^{-1}$ ],

$M_{o}$ - operator's wages including social and health insurance, $\left[€ . h^{-1}\right]$,

$R N S_{p l}$ - planned operational costs of a department,[\%]

$k_{c}$ - increment shift time, (usually 1, 11-1,15),

$\tau_{A s}$ - mach ine time,[min.]

Hourly costs to machine operation may be formulated:

$$
\begin{gathered}
N_{h s}=O_{s} k_{u s}+C_{E} \\
O_{s}=\frac{C_{s}}{Z_{s} C F S_{E F P L} \cdot S M \cdot k_{v s}}
\end{gathered}
$$

Where:

$O_{s}-$ is the write-off of a machine, $\left[€ . h^{-1}\right]$,

$C_{s}$ - a machine price, $[€]$,

$C_{E}$ - electricity price (middle value of long-term average or educated guess), $\left[€ / h^{-1}\right]$,

$Z_{s}$ - mach ine operational life in years,

$C F S_{E F P L}-$ machine time fund planned in hours per year and shift,

$S M$ - shift,

$k_{u s}$ - reparation index and mach ine maintenance index,

$k_{v s}$ - index of time-utilization of a machine,

Table 1. Approx imated values of machine time-utilizat ion index

\begin{tabular}{|c|c|}
\hline Type production & $k_{v s}$ \\
\hline Mass and large-lot production & 0,8 \\
\hline Stored programme machines, machining center & $0,65-0,75$ \\
\hline Conventional small-lot production & $0,5-0,65$ \\
\hline
\end{tabular}

Index of mach ine time-utilization (share of time when a machine works in given number of shifts to total time of scheduled shifts) is defined by long-term average eventually 
by the assumption of machine utilization. For various types of productions approximated values of the index are found in table 1.(9), (10)

Costs to devices (write-off, maintenance, potential sharpening) can be expressed as follows:

$$
N_{n}=z_{v} N_{n T}
$$

Where:

$N_{n T}$ are machine operational costs related to one device serviceability, $[€]$,

$z_{v}$ - number of the machine exchange related to one operational section (it usually is a number lower than 1).

The number of exchanges $z_{v}$ can be given by:

$$
z_{v}=\frac{\tau_{A s}}{T} k_{T}
$$

Where:

$\mathrm{T}$ is machine serviceability,[min],

$k_{T}$ - the relation of real time or more precisely the working time (when the machine deterioration is obvious) and machine time or the lenght of power run of a machine.

Costs to a machine related to a device serviceability can be given for various types of devices as follows:

For overall re-sharpening:

$N_{n T}=\frac{C_{n}-C_{z n}}{z_{0}+1}+\tau_{a s} k_{c} \frac{M_{a s}}{60}\left(1+\frac{R N O_{p l}}{100}\right) \frac{z_{0}}{z_{0}+1}(7)$

Where:

$C_{n}$ is the price of a machine, $[€]$,

$C_{z n}$-depreciated price of a machine,[€],

$M_{a s}$ - sharpener's wages including social and health insurance, $\left[€ h^{-1}\right]$,

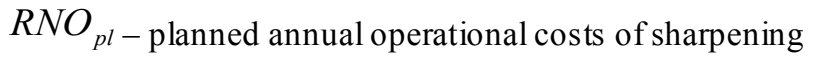
service,

$z_{0}$ - the number of possible machine re-sharpening,

$\tau_{a s}$ - time of machine sharpening, min,

For a machine with replaceable cutting plates that are not possible to be re-sharpened applies:

$$
N_{n T}=\frac{C_{p} z_{p}}{z_{h} S_{p}}+\left(1+k_{a t}\right) \frac{C_{t n}}{z_{u}}
$$

Where:

$C_{p}$ is the price of a plate, $[€]$,

$C_{t n}$ - the price of tool body, $[€]$,

$z_{p}$ - the number of cutting plates on a device,

$z_{h}$ - number of cutting edges on a plate,

$z_{u}$ - assumed number of plate clamping work whilst mach ine body serviceability,

$s_{p}$ - index of cutting plates utilization, $k_{u t}$ - index of machine body maintenance,

Approximated values of empirical constant factors of the relation are given in the table 2 . Those are statistic data.

Table 2. Approximated values of empirical constant factors

\begin{tabular}{|c|c|c|c|}
\hline Machining conditions & $z_{u}$ & $s_{p}$ & $k_{u t}$ \\
\hline Easy & $400-600$ & 0,95 & 0,05 \\
\hline Middle - difficult & $200-400$ & 0,90 & 0.025 \\
\hline Difficult & 200 & 0,80 & 0,40 \\
\hline Very difficult & 100 & 0,70 & 0,60 \\
\hline
\end{tabular}

The factor of cutting plates utilization is influenced by technological discipline, fragile plate fractions, deterioration of a new cutting edge that is not in gear, a split off splinter etc. Approximated number of gripping is normally given by random deterioration of a machine body, the index of mach ine body maintenance includes above all substitution mach ine parts.

For a machine with replaceable cutting plates that are re-sharpened is valid:

$$
\begin{aligned}
N_{n T}= & \frac{C_{p} \cdot z_{p} \cdot z_{0}}{z_{h} \cdot s_{p}\left(z_{0}+1\right)}+\left(1+k_{u t}\right) \cdot \frac{C_{t n}}{z_{u}} \\
& +\tau_{a s .} \cdot k_{c} \frac{M_{a s}}{60}\left(1+\frac{R N O_{p l}}{100}\right) \cdot \frac{z_{0}}{z_{0}+1}
\end{aligned}
$$

Where:

$z_{0}$ is the number of possible re-sharpening of a plate.

Costs to exchange of a device can be given by:

$N_{v n}$

$=\tau_{v n}\left[k_{c} \frac{M_{n}}{60} \cdot\left(1+\frac{R N S_{p l}}{100}\right)+\frac{O_{s}}{60}\right]=\tau_{v n} N_{v m n} z_{v}$

Where:

$N_{v m n}$ are costs to exchange of a device per,[min],

$M_{n}$ - wages of a setup man including social and health insurance, $\left[€^{-1}\right]$,

$\tau_{v n}$ - time to exchange a device, [ $\mathrm{min}$ ],

The criterion for minimal production costs can be given (production costs to operational department shall be minimum) by the relation (1).

Having substituted the above-mentioned relations into this criterion the optimization criterion to be reached from the point of view of production costs as follows:

$$
\begin{aligned}
& N=\tau_{A s} N_{s m}+\frac{\tau_{A s}}{T} k_{r} N_{n T}+\tau_{v n} N_{v m n} \frac{\tau_{A s}}{T} \cdot k_{r} \rightarrow \min (11) \\
& \text { Or : } \\
& N=\tau_{A s} N_{s m}+\frac{\tau_{A s}}{T} k_{r}\left(N_{n T}+\tau_{v n} N_{v m n}\right) \rightarrow \min (12)
\end{aligned}
$$

The mach ine time can be given by: 


$$
\tau_{A s}=\frac{L_{c h}}{n \cdot f}
$$

Where:

$L_{c h}$ is the length of machine automatic operation run, $[\mathrm{mm}]$,

$n$ - rotational frequency,

$f$-displacement, $[\mathrm{mm}]$

Substitution(13) in(12) results in the criterion equation:

$$
N=\frac{L_{c h}}{n . f} N_{n s}+\frac{L_{c h} k_{r}}{n \cdot f . T}\left(N_{n T}+\tau_{v n} N_{v m n}\right) \rightarrow \min (
$$

Having modified:

$$
\frac{K_{1}}{n \cdot f}+\frac{K_{2}}{n \cdot f . T} \rightarrow \min
$$

Where:

$$
\begin{gathered}
K_{1}=L_{c h} \cdot N_{s m} \\
K_{2}=L_{c h} k_{T}\left(N_{n T}+\tau_{v n} N_{v m n}\right)
\end{gathered}
$$

When milling operation, proportional parameter of displacement per rotation $f$ and displacement per tooth fz are considered. Total production costs per a work-piece can be given by the relation:

$$
N_{c}=\sum_{1}^{n u} N_{i}+N_{v}+\frac{N_{d}}{n}+\frac{N_{\check{s} z}}{n}
$$

Where:

$N_{c}$ are total production costs per a work-piece,[€],

$N_{i}$ - production costs to i- operational section, $[€]$,

$N_{\check{S} Z}$ - costs to a special device necessary for production of a given work-piece, $[€]$,

$n$ - number of produced pieces,

$n_{u}-$ number of operational sections within one work-piece,

Costs to secondary work:

$N_{v}=\tau_{A v}\left[k_{c} \frac{M_{0}}{60}\left(1+\frac{R N S_{p l}}{100}\right)+\frac{O_{s}}{60}\right]=\tau_{A s} N_{v n}$

Where:

$N_{v m}$ - costs to secondary work, $[€]$,

$\tau_{A v-\text { unit secondary time, }[\mathrm{min} .] \text {, }}$

Rate costs:

$$
N_{B}=\left[k_{c} \frac{M_{s}}{60}\left(1+\frac{R N S_{p l}}{100}\right)+\frac{O_{s}}{60}\right]=\tau_{B C} N_{B m}
$$

Where:

$N_{B m}$ are rate costs, $\left[€^{-1}\right]$,

$\tau_{B C}$ - rate time with shift time over plus,[ $\left.\mathrm{min}\right]$

Criterion of minimum production costs can be also given

by the method of hourly operational costs. (11), (12)

Fixed costs whose share in total costs continually raises are just those unwelcome costs that burden production. This is one reason why it is success to produce with optimal capacity employ ment.

For practical utilization it is appropriate to express the capacity utilization in time units (hours, norm hours). When formulating the cost model of a production workplace (of a machine) other advantageous properties of this method can be used.

1. Possibility of division (decomposition) hourly overhead lump sum into two individual units as follows:

- Into hourly overhead lump sum of joint expenses ( $\left.H R P_{s p}\right)$

- Into hourly overhead lump sum of a production workp lace (a machine) ( $H R P_{\text {pra }}$ )

2. Possibility to decompose each hourly overhead lump sum as the sole number into more partial generic cost items that enables to separately observe individual impacts on hourly overhead lump sum.(14), (15)

The first property enables to present overhead costs to particular activities within the production process with the help of hourly overhead lump sum as the total of two separable components. Total value of hourly overhead lu mp sum is consequently given by the total of both components.

While $H R P_{s p}$ will be the same for all workp laces within a single organizational unit (center, operational department, etc.) to which jo int expenses are related, the $H R P_{p r a}$ value will be unique for each workplace (machine, set of machines).

The second property allows the distinction of general expenses from the point of generic e.g. for example to components of write-offs, rent (leasing), wages, energy costs, overhead material etc. It is crucial to choose such a classification in concrete application that would respond to the situation given. It is necessary to focus on main items sensible that the less important ones can possibly be joint together. It means for example that while the significant part of a production device will not be true but rented (leased) than that item has to appear in the HRP decomposition. While the production device is true it is useless to mention the item.

The simple solution is not to divide general expenses into two parts i.e. joint expenses of a department and costs of a workplace but leave it as the average value of hourly overhead lump sum designed on the basis of share of total of all overhead costs within a department and total department capacity. It is a simple solution that can be appropriate as the first stage of transition from a calculation through an extra charge to a calculation with the usage of the hourly overhead lu mp sum method.

By this simplification the influence of individual factors is covered and their impact is not clear in the total calculation.

Essential matters for the working process optimization are a solid analysis of on what the value of expense units depends. It is determining just because the information 
enables to manage the working process effectively.

From the point of preceding ideas, there is an alternative coming out to determine minute costs to machine work (relation 2):

$$
N_{s m}=k_{c} \frac{M_{0}}{60}+\frac{H R P_{s p}}{60}+\frac{H R P_{p r a}}{60}
$$

Where:

$H R P_{s p}$ hourly absorbed lump sum of joint expenses, $\left[€ h^{-1}\right]$,

$H R P_{p r a}$ - hourly overhead lump sum of a production department (a machine), $\left[€ h^{-1}\right]$

By analogy for minute expenses to exchange of a mach ine (relation 10):

$$
N_{v m n}=k_{c} \frac{M_{s}}{60}+\frac{H R P_{s p}}{60}+\frac{H R P_{p r a}}{60}
$$

The mentioned way of how to express cost items presents the model that comes out of the dynamic calculation principle and uses the method of hourly annual lupm sums. It requires a solid analysis mainly of overhead expenses in the relation to a calculation unit. It is a model applicably open e.i. it accepts the costs units that are defined and able to find out in the application given. It relates the lowest organizational levels, it means workplaces (a machine) and a department. It concerns the open model also from the point of the possibility to enhance it by more-detailed specification of dependence of costs on cutting conditions.(1), (4)

When optimizing cutting conditions, under certain conditions it is possible to determine optimal serviceability of a machine according to a certain optimizing criterion independently on cutting condition optimization. When coming out from optimal serviceability intended from the point of minimum production costs at cutting conditions optimizing, the criterion of maximum reduction is identical with the criterion of minimum production costs.

It is possible to present the relation for optimal durability as follows:

$$
T_{\text {optN }}=\frac{\left(N_{n T}+\tau_{v n} N_{v m n}\right)}{N_{s m}} k_{r}(m-1)
$$

Where:

$T_{\text {optN }}$ is optimal serviceability of a machine from the point of production costs,[min]

$m$ - empiric constant from the Taylor's relation

Determination of optimal serviceability does not depend on cutting conditions, but leads to simplification of cutting conditions optimization. After that, it relates usage of gradual way of optimal cutting conditions setting. The procedure does not lead to optimal values.

Optimization of cutting conditions is always realized according to a optimization criterion within a restriction (restrictive conditions given by production conditions).

Working process is always limited by a certain group of restrictive conditions. It is possible to formulate these conditions mathematically as in equations. The exception is the complex Taylor's relation that is an equation.

Restrictive conditions are given by a working mach ine (its performance, cut-off twisting moment of retentive unit, cut-off size of cutting power elements, range of twists and offsets), a device (cutting material, geometry, surface roughness), material of a work-piece, cutting environment, requested qualitative parameters.

For complex optimization calculation of cutting conditions mostly linear parametric programming was used. The mathe matical apparatus comes out of linear or linearized restricting conditions. In connection with the development of production technology the utilization of non-linearized restricting conditions arose. It related for example continuous, non-linearized restricting conditions from the point of twisting moment (twist of a work-piece in a chucking device) and a bending moment (extraction of a work-piece one-sidely attached in a chucking device) by mach ines with high rotational frequency.

Apart from the continuous non-linearized restricting conditions more and more non-continuous restricting conditions occur. Before all, it relates different characteristic of wo rking mach ines performance. Mathe matical methods of cutting conditions optimization with these restricting conditions lead to interval optimization tasks.

For example, two restricting non-linearized conditions are mentioned.

For linear process of performance characteristic for performance holds the following line-equation:(14)

$$
P_{e}=k_{l} n+q_{1}
$$

Where:

$k_{1}$ and $q$ are constants.

For the process of performance it is possible to derive for example for turning operation a restricting condition as follows:

$$
a_{p}^{x_{p c}} f^{y_{p c}} n-\frac{10^{3} 60 k_{1} \eta}{k_{F c} \pi D} n \leq \frac{10^{3} 60 q_{1} \eta}{k_{F c} \pi D}
$$

At chucking devices at high rotational frequency under influence of centrifugal force opening of jaws and lowering of chucking power occurs. Even if the chucking devices are constructed specially to restrict the occurrence, at these devices it is possible to come out of the assumption that the decrease of chucking power is given by centrifugal power on jaws, at one jaw it is possible to think about dependence of chucking power $\mathrm{Fu}$ on rotational frequency $\mathrm{n}$ as follows:

$$
F_{u}=F_{u o}-k_{n} n^{n}
$$

Where:

$F_{u}$ is chucking power influencing the jaw, $[N]$,

$F_{u o}$ - chucking power influencing the jaw, yet: $n=0,[N]$,

$k_{n}$ - constant

The $C_{n}$ constant can be drawn from the details of a manufacturer as the decrease of chucking power at maximu $\mathrm{m}$ rotational frequency of a spindle. 
Table 3. Main subjects of eventual monitoring

\begin{tabular}{|c|c|c|}
\hline $\begin{array}{c}\text { Working } \\
\text { machine }\end{array}$ & $\begin{array}{c}\text { Time is critical } \\
\text { collision }\end{array}$ & Time is not critical \\
\hline $\begin{array}{c}\text { Cutting } \\
\text { machine }\end{array}$ & $\begin{array}{c}\text { Destruction of cutting } \\
\text { edge } \\
\text { Onset of a machine }\end{array}$ & $\begin{array}{c}\text { Peterision } \\
\text { Thal dilat ation } \\
\text { gusset cutt ing } \\
\text { Presence of a machine } \\
\text { Setting of a machine }\end{array}$ \\
\hline Work-piece & $\begin{array}{c}\text { Parameters of a } \\
\text { work-piece } \\
\text { Shape of a work-piece } \\
\text { Roughness of working } \\
\text { surface }\end{array}$ & $\begin{array}{c}\text { Measures of a raw } \\
\text { product } \\
\text { Working material } \\
\text { Surface integrity }\end{array}$ \\
\hline $\begin{array}{c}\text { Cutting } \\
\text { process }\end{array}$ & $\begin{array}{c}\text { Oscillation } \\
\text { Cutting power, oscillation } \\
\text { moment } \\
\text { Performance } \\
\text { Chip shaping }\end{array}$ & Cutting environment \\
\hline
\end{tabular}

From the point of maximu m acceptable rotational mo ment for 3-jaw chucking device is applicable:

$$
M_{k \max }=3 F_{u} \mu \frac{D_{u}}{2}
$$

Where:

$D_{u}$-tightening average, $[\mathrm{mm}]$,

${ }^{\mu}$ Rubbing index between a jaw and a work-piece,

After substitution and modification there are restrictive conditions as follows:

$$
a^{y F c} f^{y F c}+\frac{3 \mu D_{u} k_{n}}{k_{F c}} n^{2} \leq \frac{3 \mu D_{u} F_{u o}}{k_{F c} D}
$$

It is clear that for general optimization of cutting conditions it is important to use different mathematical apparatus from linear programming or linear parametric programming. It main ly relates the analytic methods implic it in the analysis of possible solutions; the gradient method, geometric modeling or it is also possible to use suitable optimizing software.

Win present, with regard to stochastics of cutting process it is possible to deal with optimization with the output of machine serviceability with confidence interval. The input then does not have to be the Taylor's complex relation but the table of combinations: serviceability, cutting speed, displacement, depth of cut.

It is important to emphasize on the fact that concrete data that relate given company must be brought into the optimizing software as results from preceding analysis. The results of optimizing procedures at production of the same component in various companies lead to different values of cutting conditions and to different production costs.

The important part from the point of reliab ility of working process presents it monitoring. The table 3 . introduces main subjects of eventual monitoring.[8]

From the point of optimization of machine serviceability and cutting conditions, the most important part is machine monitoring. It means the monitoring of serviceability that has certain dispersion for concrete working conditions. Afterwards, the optimization performs for center of dispersion and exchange of individual machines is determined by the monitoring device.

In the case of working without work-monitoring of a cutting machine the constant $c_{v}$ is determined with high level of security. Next, it is possible to monitor total deterioration of a machine or of parts of a cutting edge as well. Monitoring of cutting process is realized by appropriate sensors whose outputs are processed using appropriate logic.

\section{Conclusions}

Only automation of technological process, implementation of automated production machine allows to significantly increase the quality of production and its productivity and to decrease the number of service attendants and to minimalize of all costs. This article is about engeneering and economics tasks in the theory of reliability are connected with the choice of such constructional, technological and operating parameters of machines, that would provide their high technical economical indicators with considering their operational reliability. The first task is solved especially on the theoretical level and it results in working out mathematical depend anci es of reliability indicators depending on technological, constructional, structural and operating indicators of machines with regard to externalities. The process of working out such dependancies is dificult because until now the qualitative indicators of reliability have been evalueted by statistical methods.

\section{REFERENCES}

[1] AKINWUMiJU, J.A. \& Patwari, A.S. (1990) Statistical Analysis of population Data for Educational Planning in Nigeria. Faculty of Education, University of Ibadan, Nigeria 10-24.

[2] BERGELIS, A.: Impact of collaborative manufacturing engineering on production variety and efficiency. $10^{\text {th }}$ International Conference: New Ways in Manufacturing Technologies 2010, Prešov, pp. 95-102, ISBN 978-80-5530441-0

[3] BONIN, J. P., PUTTERM AN, L., Economics of Cooperation and the Labor-Managed Economy, Harwood Academic Publisher, USA, 1987.

[4] GAŠPÁR, Š. - MAŠČENIK, J. - PAŠKO, J.: The effect of degassing pressure casting molds on the quality of pressure casting. In: Advanced Materials Research. Vol. 428 (2012), p. 43-46. - ISSN 1022-6680

[5] HIRANO, H. : 5 Pillars of the visual workplace. Productivity Press, Portland, Oregon, 1998.

[6] HOSHI, T. : High productivity machining research in Japan. Journal of Applied Metal Working 4 (3), 1986, pp. 226-237

[7] HRICOVÁ, R.: Application of simulation means in computer aid of manufacturing systems control. In: TSO 2009 Proceedings - New Trends in Technical Systems Operation, 9. ročník, TU Košice, KPVP Prešov, 5. -6. novembra 2009, str. 


\section{4/117. ISBN 978-80-553-0312-3}

[8] IRELAND, N. J., Law, P. J., The Economics of LaborManaged Enterprises, St. Martin's Press, USA, 1982.

[9] LUXHOJ, J, T., RISS, J, O., THORSTEINSSON, U. : Trends and perspectives in industrial Maitenance Management. Journal of Manufacturing Systems vol. 16, 6/1997

[10] MÁDL, J. : Computer - Aided determination of machining conditions. Science Rep ort CEEPUS, Kielce 2010, pp.97-103. ISBN 978-83-88906-56-5

[11] MÁDL, J., KVASNIČKA,J. : Optimalizace obráběcího procesu. Praha, ČVUT, 1998, 168

[12] MODRÁK, V.: Functionalities and integration possibilities of manufacturing execution systems, 2009. In: Annals of Faculty of engineering Hunedoara - journal of engineering. Vol. 7, no. 1 (2009), p. 51-56. - ISSN 1584-2665, http://annals.fih.upt.ro/ANNALS-2009-1.html..

[13] MOORE, J. L. (1994) Research methods and data analysis Hull: Institute of Education, University of Hull UK. October; 9-11.

[14] MURA, L. : The network approach of internationalization study case of SME segment. In: Scientific Papers of the University of Pardubice - Series D, No. 19, Vol. XVI č. 1/2011, s. 155-161, ISSN 1211-555Xhttp://www.upce.cz/fes /veda-vyzkum/fakultni-casop isy/scip ap/posledni-obsah.pdf

[15] OPPENHEIM, A N. (1992) Questionnaire design, interviewing and attitude measurement; London \& New York: Pinter Publishers, 70 -72.

[16] Pal, D., White, M. D., "Mixed Oligopoly, Privatization, and Strategic Trade Policy", Southern Economic Association, Southern Economic Journal, vol. 65, no. 2, pp. 264-281, 1998.
[17] PUTTERMAN, L., "Labour-Managed Firms", In: Durlauf, S. N., Blume, L. E. (eds.), The New Palgrave Dictionary of Eco-nomics, Volume 4, Palgrave Macmillan, UK, pp. 791-795

[18] RAGAN, E., FEDÁK, M., OLEJÁR, T.: Analysis of the switchover point and die temperature influence on injection time with using Cad-cae systems 2011. In: Annals of Faculty of Engineering Hunedoara. Vol. 9, no. 2 (2011), p. 225-228. - ISSN 1584-2665 : http://annals.fih.upt.ro/pdf-full/ 2011/ANNALS-2011-2-45.pdf...

[19] SEBEJ, P. : The resources exploitation non-parametric statistical tests on the evaluation tendency be accounted / Peter Šebej - 2005.In: Aplimat. Part 2. - Bratislava : STU, 2005 S. 537-543. - ISBN 809692642X

[20] SEBEJ, P., HRUBINA, K., Wessely, E. : Creation of production planning using the mathematical model and multi-criterion optimalisation / P. Sebej, K. Hrubina, E. Wessely - 2004.In: Annals of DAAAM for 2004. - Vienna : DAAAM International, 2004 P. 413-414. - ISBN3901509429

[21] STEPHAN, F.H. (ed.), The Performance of Labour-M anaged Firms, Macmillan Press, UK, 1982.

[22] Vasilko, K., Bokučava, G.: Technológia automatizovanej strojárskej výroby.Bratislava, ALFA, 1991, 275 s., ISBN 80-05-00806-6

[23] VASILKO, K.: Analysis of the Impact of Cutting on Machining Process, M anufacturing Engineering, issue 1, y ear IX, 2010, pp 5-9

[24] World Bank, 2001. Global Economic prospects. Washington. D.C.

[25] WU, Y. and Zeng, L., 2008. The Impact of Trade Liberaliza-tion on the Trade balance in Developing Countries, IMF, Working Papers No.WP/08/14. 